\title{
Pathos da distância
}

\author{
João Hilton Sayeg-Siqueira
}

\section{Abertura}

s filósofos da Escola de Frankfurt (criada em 1923) propuseram releitura das condições de produção, de constituição e de ocorrência dos processos sociais, uma vez que a avaliação das leituras realizadas, até então, indicava estagnação da consciência crítica. Esse exame textual implica reflexão, análise e crítica, como forma, principalmente, de reavaliar a alienação presente nos processos sociais, estruturada pela dominação política, econômica e cultural da sociedade moderna.

Dos termos enunciados acima, pode-se entender produção como a criação de bens ou de utilidades para satisfazer as expectativas ou as necessidades humanas; constituição como a essência da criação e seus mecanismos de sustentação; e ocorrência como a comprovação de veracidade existencial de uma ação ou de um recurso. Da mesma forma, reflexão como o pensamento ponderado, discernível, que gera um comportamento prudente; análise como o exame detalhado de cada seção que compõe um todo, buscando compreender tudo aquilo que o caracteriza, seja no explícito ou nas entrelinhas; e crítica como a averiguação comprobatória da validade, dos limites e das consequências de uma ação social.

\section{Preparação}

Foram, assim, elaboradas as bases de uma teoria crítica da cultura contemporânea, divisada por Adorno e Horkheimer (1947) em três dimensões: cultura erudita, cultura popular e cultura de massa. A primeira, mais elaborada, prima por um valor estético mais requintado, por ser produzida por uma elite intelectual, mais refinada e menos intuitiva. A segunda, mais autêntica e intuitiva, é composta por menor esmero técnico e intelectual de fazer arte, vinculada às 
tradições populares. A cultura de massa, a que interessa neste trabalho, é fruto de uma fusão das duas anteriores, com alta reprodutibilidade técnica para vender uma forma inferior de arte, camuflada por uma apurada atmosfera estética, a fim de manter a população sob controle pela agradável satisfação produzida.

O principal produto da cultura de massa é a propaganda que busca estabelecer, pela propaganda oficial, um ajuste; e pela propaganda comercial, uma mudança nos hábitos. Tanto uma como outra destacam ou tentam criar um "saber-para-a-vida", apoiando, nesse propósito, seu caráter ético e fixando, no poder estético, um "modo-social-de-ser". A projeção transformadora pretendida, na oficial, é uma revelação consciente; e, na comercial, uma ilusória vantagem, estabelecida, inconscientemente, por um mundo competitivo.

Ainda, na esteira de Adorno e Horkheimer (1947), a propaganda, instrumento manipulador de falsas saídas, firma-se no fato de poder contar com a ingenuidade dos consumidores. A falaciosa verdade, uma vez que tudo que é recomendado, indistintamente, a todos, merece desconfiança, torna-se para ela um simples meio de conquistar adeptos para sua causa. Mesmo a propaganda oficial, quando agrega expectativas sociais a interesses políticos, gera confusão, porque, efetivamente, nivela as diferenças entre as valias coletiva e particular. Os interesses, quase sempre, não se harmonizam, nem mesmo quando algo sério é oferecido, pois a existência de suspeita rechaça a chancela de fidedignidade. $\mathrm{O}$ discurso da propaganda não se dirige nem às massas nem ao indivíduo, que é impotente, mas, antes, a uma testemunha imaginária da verossimilhança contida nela.

A propaganda transforma os bens da cultura em objetos, por meio da qualificação, mas há de se considerar que quanto mais qualidades forem arroladas, menor é a veracidade da informação. As épocas fazem variar o valor de verdade, pois há alternância de expectativas e de necessidades, ou se não as há, a propaganda induz a uma suposta necessidade de satisfação. A falta de compromisso e o caráter ilusório criado do objeto consistem em levar os consumidores a concordarem com os critérios ditados, seja na propaganda oficial seja na comercial, sendo que, tanto em uma quanto em outra, existe um grau de fetichização, mais baixo na primeira, mais alto na segunda.

Segundo Adorno (1938), o processo ilusório, configurado na e pela propaganda, é de fetichização que camufla os genuínos interesses na pureza do serviço prestado, a fim de exercer fascínio à produção da obra; é a substituição do dever ético que visa ao "saber-para-a-vida" pelo prazer estético que ressalta o "modo-social-de-ser". O caráter mistificador (fetichista) da realidade, aí presente, serve para coisificar o homem. Assim, frequentemente, o que constitui o significado e a característica da mensagem evidencia-se, pelo arranjo supérfluo e inútil, tão hostil ao entretenimento elevado, com a depravação do propósito 
que faz aparecer como desejável a limitação ética e como ilimitada a fruição estética. A manobra plástica de linguagens, contida na propaganda, vai contra o entretenimento elevado e invade a mensagem supostamente séria, mobilizando, no cidadão consciente, o pathos da distância.

\section{Propósito}

Pathos da distância é uma expressão anterior à Escola de Frankfurt (1923), já encontrada em Nietzsche (1888), e compreende "a vontade de ser si próprio, de destacar-se". ${ }^{1}$ A distância é esperteza e astúcia que faz com que o eu forte se preserve forte. É necessária muita astúcia para preservar a si mesmo, para se preservar elevado e diferenciar o alto entretenimento do diminuto. O pathos, nessa perspectiva, se prende à pretensão de objetividade, mas é, por sua vez, subjetivo, uma vez que oriundo de uma reflexão que norteia a adoção de procedimentos de análise, investidos, assim, de uma consciência crítica. É um exercício de lucidez que conscientiza o sujeito de que quanto mais ele se apropria das determinações do objeto, mais ele se converte, inconscientemente, em objeto, como, também, perde a autonomia na construção do conhecimento. De modo legítimo, a adoção de uma postura crítica não visa somente à autocrítica, mas também a crítica às condições de produção, de constituição e de ocorrência dos processos sociais.

Parece ser uma característica da natureza cultural, científica e artística alemã a preocupação de despertar o espírito crítico, principalmente com cunho didático, como é o caso de Brecht que propôs, na associação entre educação e teatro, o "efeito do distanciamento", utilizado para alcançar a reflexão e, assim, ativar a criticidade no espectador. É uma concepção desenvolvida em seu projeto de Teatro Épico (1936) com vistas a evidenciar o ser humano e o seu modo de ser dentro de uma ação social, o que chamou de "gestus social", significando como os homens se representam diante dos outros homens em sociedade, principalmente, pelo seu proceder (analogamente, "saber-para-a-vida" ou "modo-social-de-ser"). O "gestus" é um signo de interação social que, por extensão, pela consciência crítica do como interagir socialmente, permite olhar de forma crítica os fatos que, na maioria das vezes, passam despercebidos.

A observação do inesperado causa estranheza e desencadeia um processo que desperta o sujeito da alienação que marca o cotidiano humano. É a partir desse estranhamento que o comportamento da sociedade é analisado e uma

$1 \quad$ Nietzsche, 1888 , p. 37 
posição crítica é assumida que anula a familiaridade das situações habituais, de maneira a serem consideradas estranhas, necessitando de explicação e deixando, por isso, de serem gratuitas ou meramente naturais. A rejeição à "naturalização" dos processos sociais também está presente nas concepções de Fairclough (1992) sobre a análise de discurso.

Em um percurso de sedimentação histórica, formas particulares de representação social, de identidades, e de interação, construídas como verdades tácitas, por práticas discursivas e sociais, são ideologicamente naturalizadas. A eficácia de um processo naturalizado, convencionalizado e perpetuado discursivamente, permite que as ideologias subjacentes ao discurso, bem como relações de dominação instituídas por elas, sejam perpetradas. A revelação dessa submissão, possível pela construção de uma consciência crítica, está na descoberta do que está implícito nas entrelinhas.

O entretenimento, na indústria cultural, naturaliza comportamentos, que dificilmente possibilitam, ao consumidor, capacidade de resistência. Conforme destacam Adorno e Horkheimer (1947), sobre o significado de entretenimento, é estar de acordo, o que implica uma fuga, não da realidade, mas da ideia de resistência que ainda possa subsistir. O próprio entretenimento serve como instrumento de manipulação, pois está determinado pela lógica do mercado que o transforma em mercadoria consumível. Dessa forma, pode-se distinguir o entretenimento de alta qualidade do entretenimento da indústria cultural.

Sobre o entretenimento de alta qualidade, Cohn (1998) aponta, ao contrário do entretenimento fortuito, que ele "é uma atividade produtiva ao seu modo, que requer um investimento, consciente e, portanto, potencialmente racional, de esforço em todas as dimensões da percepção, incluindo a cognitiva." ${ }^{2}$ Em oposição, alerta que os produtos de um entretenimento diminuto são elaborados segundo os indicadores de como o bem pode ser consumido e, assim, almejam uma fruição passiva. Desse modo, o componente crítico é relegado e a percepção do consumidor se limita a uma interpretação rasteira e superficial da mensagem publicitária.

Para Adorno (1938), a interpretação ideal, diria até "perfeita e sem defeito", é aquela que identifica a manobra de coisificação pela mensagem. Há um esforço interpretativo no sentido de autorreflexão crítica do entendimento, o que traz uma correção sobre a limitação inadvertida do modelo popular, daquele que "pensa futilmente sem compromisso, justamente sem autocrítica lógica e sem confrontação com as coisas."

2 Cohn, 1998, p. 21

3 Adorno, 1938, p. 86

4 Ibid., p. 113 
O caráter estratégico e astuto do discurso da propaganda tem o objetivo de atingir o consumidor em sua veleidade de prestígio social, norteando sua interpretação, desprovida de reflexão, de análise e de crítica e fazendo com que consuma não o objeto-útil, mas o objeto-signo que distingue o indivíduo em seu "modo-social-de ser". Mas, na realidade, a criação e a reação, infundadas, de necessidade de consumo, se consolida na busca constante da sociedade de consumir objetos que tornem as pessoas diferentes, o que acaba por torná-las idênticas na adoção do mesmo "modo-social-de-ser".

O discurso da cultura de massa é caracterizado por uma confluência de linguagens e de intuitos, prestes a chamar a atenção e a persuadir o destinatário. Essas confluências criam um discurso que alia publicidade e propaganda. No dizer de Muniz (2001), a publicidade destaca os benefícios e o bem-estar que o produto veiculado pode trazer ao consumidor; e a propaganda, uma categorização diferenciadora de prestígio, pelo consumo, criando segmentações de mercado. Entende-se, por essa distinção, o porquê do enfoque de Adorno recair sobre a propaganda, posto que nela se assenta o estabelecimento de uma categorização social.

\section{Proposta}

O termo publicidade está relacionado somente às mensagens comerciais e o termo propaganda, considerado mais abrangente, liga-se à veiculação de valores ideológicos, relacionados à política, à economia e à cultura, por meio do vínculo comercial. Percebe-se que, quando o enfoque é o comércio, há um limite sutil entre os dois termos, pois atuam de forma articulada, a fim de que o consumidor adote determinadas opiniões e condutas. A propaganda visa a criar comportamentos, influenciando essas opiniões e condutas da sociedade, e a publicidade, a promover a demanda e o consumo, objetivando informar as características deste ou daquele produto. ${ }^{5}$

O tipo de discurso produzido veicula tanto uma mensagem de caráter informativo, que tem por objetivo a divulgação de um produto; quanto uma, da ordem da imposição de um sistema de valores, que tem por objetivo o consumo. Assim, o processo de produção de sentido se dá em duas direções, relacionado ao conteúdo expresso de uma mensagem primária; e, ao conteúdo induzido, principalmente nas entrelinhas, de uma mensagem secundária; o que leva o indivíduo a não comprar somente o valor de uso do produto, a sua utilização, mas

5 Muniz, 2001 
também, e substancialmente, o valor simbólico desse produto. O que importa é a meta de conquistar a memória do consumidor, estar permanentemente em sua lembrança, por meio de estratégias mnemônicas.

O sentido produzido pode ser denotado, ou seja, da ordem de uma realidade objetiva, retratada pelo plano verbal e não verbal, com um vínculo direto a um referente preciso. "Já o sentido conotado seria preenchido pelos conteúdos ideológicos, nos quais o encadeamento e a troca de significações se sucedem, num processo de produção e reprodução indefinida do código". 6

Assim concebido, esse tipo de discurso se configura numa vertente multimodal, dentro de um contexto social, com suas devidas implicações política, econômica e cultural. Qualquer análise que pretenda interpretar o fenômeno interativo da linguagem, por meio da multimodalidade textual, não pode se ater apenas ao exame da sua configuração linguística, ou apenas à classificação dos elementos linguísticos, pois interessa sobretudo desfrutar das interações múltiplas, possíveis entre os constituintes linguísticos, as representações figurativas e a interposição existente entre eles.

Esse jogo conjuntivo, no anúncio, manifesta um ato retórico que almeja, pela propaganda oficial, um convencimento racional e, pela comercial, uma persuasão emocional. Para tanto, é preciso construir uma condição de verdade, chamada, na retórica, de verossimilhança, uma vez que, tanto uma como outra, não traduz o real, mas uma concepção semiótica da realidade. Sob esse aspecto, o uso obrigatório de estratégias discursivas verbo-visuais destina-se a garantir a credibilidade do que é transmitido.

Sob a óptica argumentativa ou retórica, a linguagem presta-se a modificar crenças e comportamentos, pois é um meio político, econômico e cultural de atuação humana. Ressalte-se daí que o processo de significação de um texto deriva sobretudo do reconhecimento desse processo de interpretação das semioses, isto é, das unidades de significação, que são recursos estratégicos e que se realizam explicitamente por manifestações multimodais e que desencadeiam, também, o desvelamento de implícitos textuais, possibilitados pela congruência na troca de informações e pelo compartilhamento de convenções sociais éticas e estéticas. ${ }^{7}$

O texto, na perspectiva multimodal, projeta uma paisagem semiótica, isto é, uma composição de diferentes modos semióticos que produzem efeitos na forma e nas características do texto escrito, no qual coexistem semioses verbais e visuais. Devido a esse fator, o texto deve ser lido a partir da conjunção de

$6 \quad$ Ibid., p. 92

7 Kress; Van Leeuwen, 1996 
todos os modos de significação nele configurados. Assim, é preciso interpretar, não só as semioses verbais, mas também as semioses visuais, já que não basta apenas identificá-las, mas, associadas, lê-las e interpretá-las, para compreender as implicações discursivas.

Assim, no âmbito da interpretação, processa-se o reconhecimento das estratégias textuais multimodais utilizadas; já, no âmbito da compreensão, dá-se o reconhecimento das categorias da linguagem que possibilitam o encadeamento cognitivo, referencial e interacional processador da discursivização. Segundo esse enfoque, não se busca captar apenas o que o texto diz ou representa em termos de referência ao real, ao exterior, mas o que ele faz, como o faz e por quê o faz desse modo, já que as formas multimodais de apresentação contribuem para a construção dos efeitos de sentido. Por isso não basta ao leitor descodificar os elementos linguísticos, é preciso captar o universo textual como um todo e isso abrange reconhecer o conjunto de estratégias multimodais discursivas adotadas.

Dessa forma, associando aspectos que concernem à Escola de Frankfurt à configuração do discurso da propaganda, à multimodalidade configurativa do texto e às estratégias retóricas de argumentação, propõem-se, para a análise do texto verbo-visual da propaganda, um procedimento metodológico que visa a identificar as semioses, como unidades de interpretação significativa, na paisagem semiótica textual e que, para tanto, é estabelecido pelas seguintes categorias:

1. produção: criação de bens ou de utilidades para satisfazer as expectativas ou as necessidades humanas;

1.1 semioses verbais:

1.2 semioses visuais:

2. constituição: a essência da criação e seus mecanismos de sustentação;

2.1 semioses verbais:

2.2 semioses visuais:

2.3 estratégias argumentativas:

3. ocorrência: a comprovação de veracidade existencial de uma ação ou de um recurso;

3.1 semioses verbais:

3.2 semioses visuais:

4.leitura reflexiva da fetichização:

4.1 semioses verbais:

4.2 semioses visuais:

5. análise do explícito e das entrelinhas:

5.1 semioses verbais:

5.2 semioses visuais:

6. crítica de verificação comprobatória da validade:

6.1 semioses verbais: 


\section{2 semioses visuais:}

7. pathos da distância:

7.1 semioses do saber-para-a-vida:

7.2 semioses do modo-social-de-ser:

\section{Aplicação}

Foram selecionadas duas peças de propaganda, uma, oficial, sobre recrutamento de cidadãos a se mobilizarem em favor da preservação da natureza; e outra, comercial, sobre o lançamento de um perfume masculino.

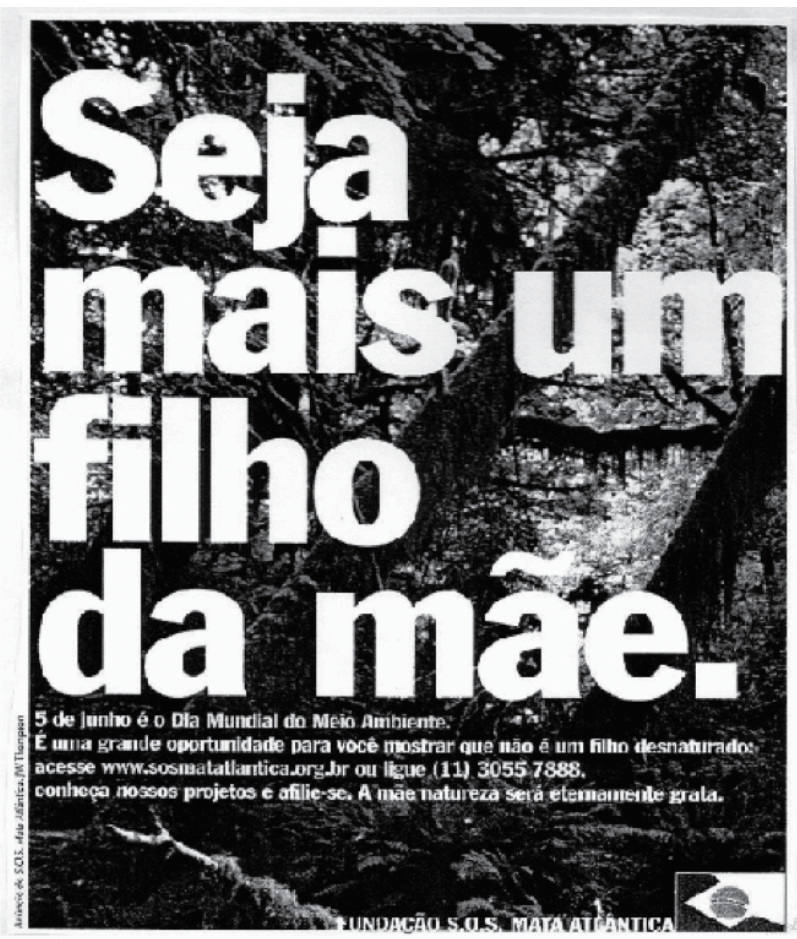

5 de junho é o Dia Mundial do Meio Ambiente.

É uma grande oportunidade para você mostrar que não é um filho desnaturado: acesse www.sosmatatlantica.org.br ou ligue (11) 3055 7888, conheça nossos projetos e afilie-se. A mãe natureza será eternamente grata. FUNDAÇÃO S.O.S MATA ATLÂNTICA

Época, São Paulo: Globo, 264, 9 jun. 2003. 
1. produção: criação de bens ou de utilidades para satisfazer as expectativas ou as necessidades humanas;

1.1 semioses verbais: "oportunidade para você mostrar que não é filho desnaturado" - é criada uma circunstância favorável para a realização de algo útil à natureza e, por extensão, a si e à humanidade;

1.2 semioses visuais: a paisagem em preto e branco está em busca de benfeitores para recuperar o viço das cores exuberantes, caracterizadoras da natureza, pelo que "será eternamente grata";

2. constituição: a essência da criação e seus mecanismos de sustentação;

2.1 semioses verbais: não ser um "filho desnaturado", ser sensível ao apelo, na data em que se comemora o Dia Mundial do Meio Ambiente;

2.2 semioses visuais: o meio ambiente descolorido é o suporte para o texto verbal, numa simbiose de invocação;

2.3 estratégias argumentativas: o texto verbal começa com uma informação, a data da comemoração que é engrandecida por um argumento de avaliação, que destaca o que há de bom no Dia Mundial do Meio Ambiente, ser uma "grande oportunidade", que oferece, por meio de um argumento de comportamento valorativo, uma finalidade positiva, "para você mostrar" um comportamento virtuoso de que "não é um filho desnaturado". Para que a virtude se efetive é necessária uma ação determinativa, configurada pelo argumento de convicção e dada pelos verbos no imperativo "conheça" e "afilie-se". A caixa de texto tem por fechamento dois argumentos por simbologia, um pela metáfora "mãe natureza" e outro pela prosopopeia "mãe natureza será (...) grata"; este assegurado pelo argumento de persistência, "eternamente". O uso conotativo da linguagem destaca, da natureza, sua condição de ser vivo e, assim, reforça a finalidade de convencer o leitor a atender o chamamento;

3. ocorrência: a comprovação de veracidade existencial de uma ação ou de um recurso;

3.1 semioses verbais: assinatura da peça pela Fundação S.O.S. Mata Atlântica;

3.2 semioses visuais: estampa do selo nacional de certificação, com o pavilhão nacional;

4. leitura reflexiva da fetichização:

4.1 semioses verbais: o slogan, "Seja um filho da mãe", tem um duplo sentido, um pejorativo, que leva o leitor ao recuo; outro aclamatório, que busca o engajamento do leitor na causa assinalada. Esse jogo de interpretações provoca, no leitor, um estranhamento, ponto inicial para o desenvolvimento de uma reflexão que, possivelmente, leve a uma postura crítica;

4.2 semioses visuais: a associação de cada um desses sentidos a um contexto particular de desolação, dado pelo suporte figurativo, que retrata uma natureza esquálida, direciona, o leitor, a uma conduta reflexiva; 
5. análise do explícito e das entrelinhas:

5.1 semioses verbais: no explícito, pela tradição popular, lê-se, de imediato, um insulto; o leitor se sente depreciado, o que pode levá-lo a um desafio a se interessar pela leitura do texto, uma vez que toda ação provoca uma reação. Ao ler a mensagem da caixa de texto, o slogan ganha uma nova configuração significativa, a de saudação, em busca da aprovação do mérito da campanha;

5.2 semioses visuais: os caules tombados denotam um abate, mas, ao mesmo tempo, pelo enquadramento em contra-plongée; se "plongée", em francês, significa mergulho, o ângulo contrário, de baixo para cima, significa emersão, o que traz a sensação exaltativa de superioridade; é um gigante em agonia que o leitor, diminuto, aqui embaixo, tem o poder de salvar;

6. crítica de verificação comprobatória da validade:

6.1 semioses verbais: o uso do duplo sentido causa estranhamento explícito, mas, como todo signo é, em essência, polissêmico, pelo implícito, tem-se uma interpretação diferente, que consolida o objetivo da campanha em busca de um leitor que entenda a natureza como mãe, e participe de projetos para a preservação do meio ambiente;

6.2 semioses visuais: a assinatura da peça em caixa alta enfatiza a grandeza e a solidez da fundação que promove a campanha, que é chancelada pelo selo nacional de certificação;

7. pathos da distância: houve um processo de construção reflexiva, desencadeada pela própria configuração da peça, o que suscitou, pelo estranhamento, análise e posicionamento crítico, que solicita, do leitor, uma vontade, não de consumir, mas de ser pelas:

7.1 semioses do saber-para-a-vida: conscientização da importância de preservação da natureza para a preservação de todas as espécies vivas, uma vez que a natureza é a provedora de todas as vidas, portanto é uma propaganda oficial que abre diálogo para o contraditório e possibilita, assim, o distanciamento;

7.2 semioses do modo-social-de-ser: participação em causas sociais, políticas, econômicas e culturais; que garantam a preservação e o bem-estar dos seres vivos; portanto, é um engajamento ciente e não um mero consumo de produto. 


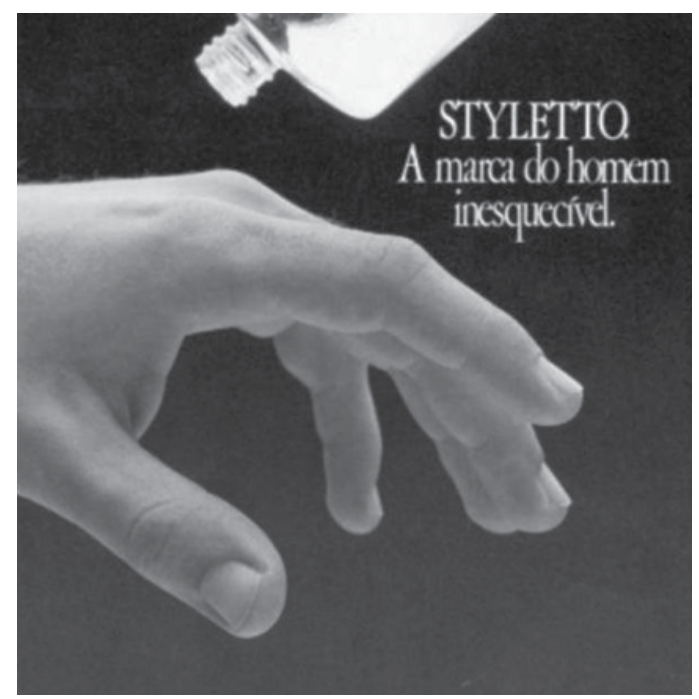

Lançamento da linha Styletto, em 1985, por O Boticário

1. produção: criação de bens ou de utilidades para satisfazer as expectativas ou as necessidades humanas;

1.1 semioses verbais: "homem inesquecível" - é estabelecida uma meta de durabilidade como expectativa para os consumidores; perdurar é objetivo tanto do usuário, quanto do produto, que tem na qualidade não só o aroma, mas também o fixador; é, portanto, o perfume que fixa o homem;

1.2 semioses visuais: não é mostrada a embalagem do perfume nem o rótulo com a logomarca, apenas o bico dosador, que possibilita identificar o produto como sendo perfume e que quer mostrar que basta uma gota em apenas uma parte do corpo, no caso, as mãos, para deixar a marca do perfume e do homem;

2. constituição: a essência da criação e seus mecanismos de sustentação;

2.1 semioses verbais: Styletto é o produto e ponto final; após a marca, há um ponto final, de difícil ocorrência em marcas, títulos e slogans; é como se a mensagem fosse: Styletto e ponto final; basta por si;

2.2 semioses visuais: a marca aparece em destaque, em caixa alta com fonte maior, encabeçando o anúncio; é a projeção do produto pela marca, recurso metonímico de que Styletto é sinônimo de perfume, um equivale ao outro;

2.3 estratégias argumentativas: o texto que serve como slogan, "A marca do homem inesquecível., traz, inicialmente, "A marca", antecedida por um artigo definido, como a indicar, por meio de um argumento de avaliação enaltecedora, que ela é única, definitiva; assim, "marca” tem um valor argumentativo de avaliação valorativa, indicadora de um traço, uma impressão, um sinal indeléveis, 
deixados tanto pelo perfume, quanto pelo homem que o usa e que é firme e duradouro; por isso, o "homem inesquecível" é memorável, argumento ilustrativo, com duplo sentido, pois o indivíduo não fica registrado só na memória olfativa, mas também se destaca dentre todos os outros;

3. ocorrência: a comprovação de veracidade existencial de uma ação ou de um recurso;

3.1 semioses verbais: "A marca" é uma referência distintiva, registrada, pelo fabricante O Boticário, símbolo especial de um fabricante de renome; pelo nome do produto, do latim stilus, nome dado, na antiguidade, ao ponteiro, usado para escrever; assim, como a escrita, o perfume não se dissipa, fica registrado permanente e se torna um hábito, do qual não mais se desprende. Stilus como ponteiro, deu origem, também, à palavra estilete, no italiano stiletto, punhal muito estreito e afiado;

3.2 semioses visuais: o produto deixa, também, visualmente, sua marca, pelo nome, ao ser registrado com ípsilon (y);

4. leitura reflexiva da fetichização:

4.1 semioses verbais: “A marca do homem inesquecível." é um slogan que destaca que o homem, para ser inesquecível, precisa ter, ou deixar, uma marca e que é por meio do consumo que isso será conseguido; é a fetichização comercial;

4.2 semioses visuais: a mão é colocada numa posição descensional, desinteressada de praticar uma ação; é uma fetichização apassivadora de uma mão receptora, talvez entorpecida pela fragrância ou à espera de um balsâmico tônico;

5. análise do explícito e das entrelinhas:

5.1 semioses verbais: há um encadeamento nominal de explicitações e de caracterizações, em que "marca" é determinada e modificada: é a marca definitiva de masculinidade; portanto, é uma marca única para o homem, que, também, é único, pois, da mesma forma vem determinado e modificado: o homem inesquecível; ou seja, de presença constante

5.2 semioses visuais: o anúncio é clean, em preto e branco, como se esperasse a gota do perfume para se encandecer e ganhar colorido; assim, o homem, também, ganhará fulgor e mais vitalidade na mão, ao receber a aplicação da essência;

6. crítica de verificação comprobatória da validade:

6.1 semioses verbais: por o anúncio ser enxuto e direto, não deixa margens para questionamentos, pois, como foi visto, na seção anterior, quanto mais qualidades são arroladas, mais desconfiança gera; um produto eficiente se coaduna com as características masculinas, quando basta por si e ponto final, sem muitas delongas, o que reflete independência; quando basta ser parcimonioso, 
pois um pequeno gesto já demonstra coragem e firmeza de caráter; e quando basta ser positivo nas decisões e nas avaliações, o que denota assertividade; essa é a mensagem de validação da marca e do fabricante, uma vez que ele, por extensão, ao lançar um produto para o consumo do homem, com refinada qualidade, assevera independência, coragem e assertividade;

6.2 semioses visuais: a mão está numa posição de receptora e não de concessora viril, própria do homem, ou seja, um instrumento de força para o labor e para a luta; talvez, como já visto anteriormente, só assim o será, se receber as benesses vitais do produto, o que o induz ao consumo;

7. pathos da distância:

7.1 semioses do saber-para-a-vida: por ser uma propaganda comercial, não agrega conhecimento, mas um envolvimento emocional, o que, simplesmente, induz ao consumo e dificulta o distanciamento; a não ser em casos específicos, como deste artigo, em que o propósito é tentar fazer uma análise fria com procedimentos de reflexão, análise e crítica;

7.2 semioses do modo-social-de-ser: Styletto. A marca do homem inesquecível. - um slogan muito conciso no dizer e no significar, o que não abre em argumentos para o contraditório, só para a impassível aceitação.

\section{Finalização}

"Quem conta um conto, aumenta um ponto." Ficam aqui minhas desculpas pela ousadia de apresentar resultados de leituras, de interpretações e de compreensões sobre vertentes teóricas, autores e conceitos, nem sempre fieis, mas buscando, por meio da reflexão, ponderação, discernimento e prudência; por meio da análise, compreensão, teórica e prática, dos explícitos e dos implícitos de cada mensagem; e por meio de uma postura crítica, averiguar a validade, os limites e as consequências de cada passo dado, seja na abordagem dos conceitos selecionados, seja no estabelecimento e na aplicação das categorias de análise.

O intuito foi apresentar a noção do "pathos da distância”, visando a ponderações sobre esse posicionamento frente ao caráter fetichista da propaganda, artimanha que é ao mesmo tempo manifesta e oculta na paisagem semiótica do anúncio. Essa simulação para ocultação da intencionalidade comercial provoca uma tensão entre essência e aparência. No entanto, a conscientização, perfeitamente sintonizada com o engodo fetichizado, leva o consumidor a um afastamento que revela, inteiramente, a impossibilidade de a aparência ser um testemunho válido da essência, é, portanto, uma desnaturalização dos processos socialmente naturalizados por valores políticos, econômicos e culturais. 


\section{Referências}

ADORNO, T. (1938) O fetichismo na música e a regressão da audição. In Adorno vida e obra. São Paulo: Editora Nova Cultural Ltda., uma divisão do Círculo do Livro Ltda. 1996.

. (1961) Introdução à controvérsia sobre o positivismo na sociologia alemã. In Adorno - vida e obra. São Paulo: Editora Nova Cultural Ltda., uma divisão do Círculo do Livro Ltda. 1996.

. (1996) Vida e obra. São Paulo: Editora Nova Cultural Ltda., uma divisão do Círculo do Livro Ltda. 1996.

ADORNO, T.; HORKHEIMER, M. (1947) Dialética do esclarecimento. Fragmentos filosóficos. Rio de Janeiro: Jorge Zahar, 1985.

BRECHT, B. (1936) Teatro dialético: ensaios. Rio de Janeiro: Civilização Brasileira, 1967

COHN, G. (1998). A atualidade do conceito de indústria cultural. In Sociedade global, cultura e religião. Petrópolis: Editora Vozes, p. 11-26.

FAIRCLOUGH, N. (1992) Discurso e mudança social. Brasília: Editora da UNB, 2001.

KRESS, G; VAN LEEUWEN, T. (1996) Reading images: the grammar of visual design. London: Routledge.

MUNIZ, E. (2001) Comunicação publicitária, a linguagem simbólica do consumo. In Tendências na comunicação, $\mathrm{n}^{\circ}$ 4, Porto Alegre, Ed. L\&PM e RBS, p. 92-103, 2001.

NIETZSCHE, F. (1888) Crepúsculo dos ídolos: ou como se filosofa com o martelo. São Paulo: Companhia das Letras, 2006.

. Fragmentos do espólio: primavera de 1884 a outono de 1885. Brasília, Ed.

$\overline{\mathrm{UnB}}, 2008$. 